\title{
Preparation and Characterization of a Polyclonal Antibody against Brominated Protein
}

\author{
Yasuhiro Kambayashi', Keiki Ogino, ${ }^{2, *}$, Kei Takemoto ${ }^{2}$, Takashi Imagama ${ }^{3}$, Tomoko Takigawa ${ }^{2}$, \\ Shingo Kimura ${ }^{1}$, Yuri Hibino ${ }^{1}$, Yoshiaki Hitomi ${ }^{1}$, and Hiroyuki Nakamura ${ }^{1}$ \\ ${ }^{1}$ Department of Environmental and Preventive Medicine, Graduate School of Medical Science, \\ Kanazawa University, 13-1 Takara-machi, Kanazawa 920-8640, Japan \\ ${ }^{2}$ Department of Public Health, Okayama University Graduate School of Medicine, Density, \\ and Pharmaceutical Sciences, 2-5-1 Shikata-cho, Okayama 700-8558, Japan \\ ${ }^{3}$ Department of Orthopedic Surgery, Yamaguchi School of Medicine, 1-1-1 Minami-Kogushi, Ube 755-8505, Japan
}

Received 24 July, 2008; Accepted 26 September, 2008

\begin{abstract}
Summary (Di)bromotyrosine is formed by the specific reaction of eosinophil peroxidase and can be used as an eosinophil activation marker. In the present study, an antibody for (di)bromotyrosine in proteins was prepared to investigate the pathogenesis of eosinophilrelated diseases such as allergic responses. A rabbit polyclonal antibody was raised against brominated keyhole limpet hemocyanin. The specificity of the antiserum was investigated with an enzyme-linked immunosorbent assay (ELISA). The antiserum recognized brominated bovine serum albumin (BSA) and dibromotyrosine-conjugated BSA. The antiserum also reacted with chlorinated BSA and di-iodotyrosine-conjugated BSA. Moreover, the specificity of the antiserum was investigated using competitive ELISA. Dibromotyrosine and diiodotyrosine inhibited the recognition of brominated BSA by the antiserum. However, the recognition of brominated BSA by the antiserum was not inhibited by bromotyrosine, chlorotyrosine, iodotyrosine, nitrotyrosine, aminotyrosine, phosphotyrosine, or tyrosine. These results suggested that the epitope of the antiserum is dihalogenated tyrosine. Immunohistochemically, the antiserum stained brominated rat eosinophils but not chlorinated or nitrated eosinophils. In conclusion, an antiserum for dihalogenated protein was prepared. It is expected that the antiserum will be useful for the analysis of the pathogenesis of allergic diseases such as asthma and atopic dermatitis.
\end{abstract}

Key Words: (di)bromotyrosine, eosinophil activation marker, polyclonal antibody, allergic disease, oxidative stress

\section{Introduction}

Eosinophils play a pivotal role in host defense, such as in killing invasive parasites [1]. Eosinophils are also involved in the pathophysiology of allergic diseases [1-5]. When

\footnotetext{
*To whom correspondence should be addressed.

Tel: +81862357184 Fax: +81862260715

E-mail: kogino@md.okayama-u.ac.jp
}

eosinophils are activated, eosinophil-specific granule proteins (eosinophil peroxidase (EPO), major basic protein, eosinophil cationic protein, and eosinophil-derived neurotoxin) are released and proceed to induce tissue damage.

Halogenated tyrosine is formed by the specific reaction of myeloperoxidase (MPO), a neutrophil specific enzyme [6-8], and EPO [9]. MPO prefers chloride $\left(\mathrm{Cl}^{-}\right)$to bromide $\left(\mathrm{Br}^{-}\right)$as a substrate and produces hypochlorous acid ( $\mathrm{HOCl}$ ) (equation 1) $[2,10-14]$. In contrast, EPO prefers $\mathrm{Br}^{-}$to $\mathrm{Cl}^{-}$as a substrate and produces hypobromous acid ( $\mathrm{HOBr}$ ) (equation 
2) $[2,9,13,15]$. $\mathrm{HOCl}$ and $\mathrm{HOBr}$ halogenate tyrosine (Tyr) residues and produce chlorotyrosine (Cl-Tyr) and bromotyrosine (Br-Tyr), respectively (equation 3). Dibromotyrosine (diBr-Tyr) is also formed by the bromination of $\mathrm{Br}-\mathrm{Tyr}$ by $\mathrm{HOBr}$ (equation 4). When EPO is activated, both Br-Tyr and diBr-Tyr are formed.

$$
\begin{aligned}
& \mathrm{MPO}+\mathrm{H}_{2} \mathrm{O}_{2}+\mathrm{Cl}^{-} \rightarrow \mathrm{HOCl}(1) \\
& \mathrm{EPO}+\mathrm{H}_{2} \mathrm{O}_{2}+\mathrm{Br}^{-} \rightarrow \mathrm{HOBr}(2) \\
& \mathrm{Tyr}+\mathrm{HOCl}(\mathrm{HOBr}) \rightarrow \mathrm{Cl}-\mathrm{Tyr}(\mathrm{Br}-\mathrm{Tyr})(3) \\
& \mathrm{Br}-\mathrm{Tyr}+\mathrm{HOBr} \rightarrow \text { diBr-Tyr (4) }
\end{aligned}
$$

Several reports indicate that both EPO and MPO produce $\mathrm{HOCl}$ and $\mathrm{HOBr}$ in vitro [16-19]. However, a study using EPO-knockout mice and MPO-knockout mice showed clearly that the source of Br-Tyr is EPO, and that of Cl-Tyr is MPO in vivo [20]. Therefore, (di)Br-Tyr is expected to be useable as a marker for eosinophil activation in vivo [9]. In fact, high levels of Br-Tyr in the urine, endotracheal/bronchial aspirate, and sputum of asthma patients have been reported $[2,21,22]$. In these reports, bromotyrosine was measured by gas chromatography/mass spectrometry. If an antibody for (di)Br-Tyr is obtained, it will be useful for investigation of the pathogenesis of eosinophil-related allergic diseases such as asthma and atopic dermatitis. Thus, this study attempted to prepare a specific polyclonal antibody for (di)Br-Tyr.

\section{Materials and Methods}

\section{Reagents}

Bovine serum albumin (BSA), Tyr, 3,5-diiode-L-tyrosine (diI-Tyr) dihydrate, 3-nitro-L-tyrosine $\left(\mathrm{NO}_{2}\right.$-Tyr), Cl-Tyr hydrochloride, and $O$-phospho-L-tyrosine (P-Tyr) were purchased from Sigma Chemical Co. (St. Louis, MO). 3Amino-L-tyrosine ( $\left.\mathrm{NH}_{2}-\mathrm{Tyr}\right)$ dihydrochloride, iodotyrosine (I-Tyr), and 3-chloro-4-hydroxybenzoic acid (Cl-HBA) were from Aldrich Chemical Company, Inc. (Milwaukee, WI). 3,5-Dibromo-L-tyrosine (diBr-Tyr), 3,5-dibromo-4hydroxybenzoic acid (diBr-HBA), 3,5-dichloro-4hydroxybenzoic acid (diCl-HBA), 3-nitro-4-hydroxybenzoic acid ( $\mathrm{NO}_{2}$-HBA), and 3-amino-4-hydroxybenzoic acid $\left(\mathrm{NH}_{2}-\mathrm{HBA}\right)$ were from Tokyo Kasei Kogyo Co. Ltd. (Tokyo, Japan). 3-Bromo-4-hydroxybenzoic acid (Br-HBA), sodium hypochlorite, hydrogen peroxide $\left(\mathrm{H}_{2} \mathrm{O}_{2}\right)$, and normal goat serum were obtained from Wako Pure Chemical Industries, Ltd. (Osaka, Japan). 3,5-Dinitro-4-hyrdroyxybenzoic acid (diNO2-HBA) was from AVOCADO Research Chemicals, Ltd. (Lancashire, UK). Peroxynitrite, diethylenetriamine$N, N, N^{\prime}, N^{\prime \prime}, N^{\prime \prime}$-pentaacetic acid (DTPA), and $N$-(6maleimidocaproyloxy)-succinimide (EMCS) were from Dojindo Laboratories (Kumamoto, Japan). Imject ${ }^{\circledR}$ mariculture keyhole limpet hemocyanin (KLH), Freund's complete adjuvant, Freund's incomplete adjuvant, $\mathrm{N}$-succinimidyl 3(2-pyridyldithio)propionate (SPDP), and 1-ethyl-3-(3dimethylaminopropyl) carbodiimide hydrochloride (EDC) were from PIERCE Biotechnology, Inc. (Rockford, IL, USA). Sodium hypobromite was from Kanto Chemical Co., Ltd. (Tokyo, Japan). Solvents and other reagents were of the highest grade commercially available. The absorbance of hypochlorite and hypobromite were measured spectrophotometrically and their concentrations were calculated from their molar extinction coefficients $\left(\varepsilon_{292 \mathrm{~nm}}=350 \mathrm{M}^{-1} \mathrm{~cm}^{-1}\right.$ [23] and $\varepsilon_{331 \mathrm{~nm}}=315 \mathrm{M}^{-1} \mathrm{~cm}^{-1}$ [24], respectively). Br-Tyr was prepared by the bromination of Tyr using sodium hypobromite and purified by high performance liquid chromatography (HPLC).

\section{Animals}

Japanese white rabbits were purchased from Kiwa Laboratory Animals Co., Ltd. (Wakayama, Japan). Wistar rats were purchased from Shiroishi Lab. Animal Reproduction Inc. (Tokyo, Japan). The care and handling of the animals were in accordance with the Guidelines for the Care and Use of Laboratory Animals of Kanazawa University.

\section{Preparation of modified protein}

One millimolar sodium hypobromite or $5 \mathrm{mM}$ sodium hypochlorite was added to $5 \mathrm{mg} / \mathrm{ml} \mathrm{BSA}$ or $\mathrm{KLH}$ at room temperature. After dialysis with $10 \mathrm{mM}$ phosphate-buffered saline ( $\mathrm{pH}$ 7.2), a part of the modified protein was digested with pronase (Roche Diagnostics, Basel, Switzerland). BrTyr and Cl-Tyr were analyzed by HPLC to confirm the bromination and chlorination, respectively, of tyrosine in the proteins. Water/methanol/acetic acid $(=97 / 3 / 0.1, \mathrm{v} / \mathrm{v} / \mathrm{v})$ and a CAPCELPAK C18 column $(4.6 \times 250 \mathrm{~mm}, 5 \mu \mathrm{m}$, Shiseido Co., Ltd., Tokyo, Japan) were used as the mobile phase and column, respectively. DiBr-Tyr was analyzed by HPLC to confirm the dibromination of tyrosine in the proteins. Water/methanol/acetic acid $(=80 / 20 / 0.1, \mathrm{v} / \mathrm{v} / \mathrm{v})$ and a CAPCELPAK C18 column $(4.6 \times 250 \mathrm{~mm}, 5 \mu \mathrm{m}$, Shiseido Co., Ltd., Tokyo, Japan) were used as the mobile phase and column, respectively. Modified tyrosine was detected at $274 \mathrm{~nm}$. Nitrated BSA was prepared by the reaction of $5 \mathrm{mg} / \mathrm{ml}$ BSA with $1 \mathrm{mM}$ peroxynitrite. Tyr or modified Tyr was conjugated with BSA using SPDP and EMCS as reported previously [25]. Modified hydroxybenzoic acid (HBA) was conjugated with BSA using EDC as reported previously [26]. After dialysis, the concentrations of the modified BSAs were determined by the Bradford protein quantitation assay (Bio-Rad Laboratories, Hercules, CA).

\section{Immunization}

Brominated KLH $(500 \mu \mathrm{g})$ as an immunogen in $2 \mathrm{ml}$ of $10 \mathrm{mM}$ phosphate-buffered saline ( $\mathrm{pH}$ 7.2) was mixed with $4 \mathrm{ml}$ of Freund's complete adjuvant (first injection) or Freund's incomplete adjuvant (booster injections). Arterial blood was drawn from the ear of the rabbit before the administration of the immunogen subcutaneously at 2 week 
intervals. The titer of the antiserum was examined using an enzyme-linked immunosorbent assay (ELISA).

\section{ELISA}

Five hundred nanograms of antigen dissolved in $60 \mathrm{mM}$ carbonate buffer ( $\mathrm{pH}$ 9.6) was added to each well of a 96 well microplate and incubated at $4{ }^{\circ} \mathrm{C}$ overnight. Three percent skim milk in $10 \mathrm{mM}$ Tris-buffered saline was used for the blocking of non-specific binding. The rabbit antiserum $(1: 3,000)$ was used as a primary antibody and horseradish peroxidase-conjugated goat anti-rabbitimmunoglobulin (1:2,000, Dako Cytomation, Glostrup, Denmark) as a secondary antibody. Visualization was performed using a Colorimetric kit T (Sumitomo Bakelite Co., Ltd., Tokyo, Japan). The absorbance at $450 \mathrm{~nm}$ was measured using a microplate reader. When competitive ELISA was performed, the antiserum was preincubated with competitor for $2 \mathrm{~h}$. The $\mathrm{pH}$ of each competitor solution was adjusted to 7.4 before addition to the antiserum.

\section{Immunohistochemistry}

Horse serum was injected intraperitoneally into a rat every 3 days [27]. At $24 \mathrm{~h}$ after the third injection, peritoneal exudate cells were collected by washing the abdominal cavity with Hanks' balanced salt solution. On a cytospin slide $\left(2 \times 10^{5}\right.$ cells), rat eosinophils were stained with Luxol fast blue. The cytospin slides (with eosinophil-containing cells) were incubated with $100 \mu \mathrm{M}$ sodium bromide, $140 \mathrm{mM}$ sodium chloride, or $50 \mu \mathrm{M}$ sodium nitrite in the presence of $100 \mu \mathrm{M}$ DTPA plus $100 \mu \mathrm{M} \mathrm{H}_{2} \mathrm{O}_{2}$ in $50 \mathrm{mM}$ potassium phosphate buffer $\left(\mathrm{pH} \mathrm{7.4)}\right.$ ) for $5 \mathrm{~min}$ at $37^{\circ} \mathrm{C}$. Control specimens were incubated with $100 \mu \mathrm{M}$ DTPA or $100 \mu \mathrm{M}$ DTPA plus $100 \mu \mathrm{M} \mathrm{H}_{2} \mathrm{O}_{2}$. Cells were fixed with $10 \%$ formalin. Endogenous peroxidase activity was blocked with $0.3 \% \mathrm{H}_{2} \mathrm{O}_{2}$-containing methanol. Five percent normal goat serum was used to block non-specific binding. The rabbit antiserum $(1: 4,000)$ was incubated with specimens at $4{ }^{\circ} \mathrm{C}$ overnight. As a secondary antibody, anti-rabbit immunoglobulin antibody with horseradish peroxidaselabeled dextran polymer (1:16, Dako Cytomation) was used. Staining was performed by the reaction with 3,3'diaminobenzidine tetrahydrochloride and $\mathrm{H}_{2} \mathrm{O}_{2}$. The cells were counterstained with hematoxylin.

\section{Statistical analysis}

Statistical analysis of the differences in the mean values was performed by two-way analysis of variance (ANOVA) and one-way ANOVA, followed by the Tukey's post hoc test using SPSS 11.5 software (SPSS, Chicago, IL).

\section{Results}

\section{Synthesis of the immunogen and antigens}

KLH was brominated using $\mathrm{HOBr}$ (Fig. 1a). An analytical method for various modified Tyr residues using HPLC was developed to confirm the bromination of Tyr in brominated $\mathrm{KLH}$. The retention times of Tyr, Cl-Tyr, $\mathrm{Br}-\mathrm{Tyr}$, and $\mathrm{NO}_{2}-$ Tyr were 5.9, 14.9, 20.1, and $20.9 \mathrm{~min}$, respectively (Fig. 2A). Another analytical method for diBr-Tyr (retention time: $11.1 \mathrm{~min}$ ) was also developed (Fig. 2C). Using these methods, the pronase hydrolysate of brominated KLH was analyzed (Fig. 2B and D). Br-Tyr and diBr-Tyr were formed in $\mathrm{KLH}$ but Cl-Tyr and $\mathrm{NO}_{2}$-Tyr were not observed in the hydrolysate. Therefore, brominated KLH was used as the immunogen. Modified BSA, modified Tyr-conjugated BSA and modified HBA-conjugated BSA as antigens for ELISA were synthesized as described in the "Materials and Methods" section (Fig. 1a-c).

\section{Characteristics of the antiserum: ELISA}

Rabbit antiserum raised against brominated KLH was obtained, and the reactivity of the antiserum was investigated using ELISA (Fig. 3A). The recognition of brominated BSA by the antiserum $(1: 3,000)$ was proportional to the antigen concentrations and reached a plateau at $500 \mathrm{ng} /$ well. In contrast, the antiserum did not recognize BSA. The titer of the antiserum was examined (Fig. 3B). The recognition of brominated BSA by the antiserum was inversely proportional to the dilution ratio of the antiserum. When a high concentration of antiserum was used, it recognized BSA very weakly. However, when 3,000-fold-diluted antiserum was used, the recognition of BSA was negligible. Thus, the optimum concentrations of the antigen and antiserum for ELISA were determined to be $500 \mathrm{ng} /$ well and 1:3,000, respectively.

The antigen specificity of the antiserum was investigated using various modified BSAs as antigens for ELISA (Fig. 4). The antiserum recognized brominated BSA and diBr-Tyr-conjugated BSA. However, it did not recognize diBr-HBA-conjugated BSA. The antiserum reacted with diI-Tyr-conjugated BSA and chlorinated BSA. Weak recognition of Br-Tyr-conjugated BSA and Cl-Tyr-conjugated BSA by the antiserum was observed, but its level was the same as that of the recognition of Tyr-conjugated BSA by the antiserum. $\mathrm{NO}_{2}-\mathrm{Tyr}$ can be formed in vivo via peroxidase-catalyzed nitration of Tyr. $\mathrm{NH}_{2}-\mathrm{Tyr}$ was also formed in vivo via the reduction of $\mathrm{NO}_{2}$-Tyr. The antiserum weakly recognized $\mathrm{NO}_{2}$-Tyr-conjugated $\mathrm{BSA}$ and $\mathrm{NH}_{2}$-Tyrconjugated BSA, but it did not react with nitrated BSA, Br-HBA-conjugated BSA, diCl-HBA-conjugate BSA, ClHBA-conjugated BSA, $\mathrm{NO}_{2}$-HBA-conjugated $\mathrm{BSA}, \mathrm{NH}_{2}-$ HBA-conjugated BSA, or BSA. These results suggest that the antiserum recognized dihalogenated tyrosine. 
a)

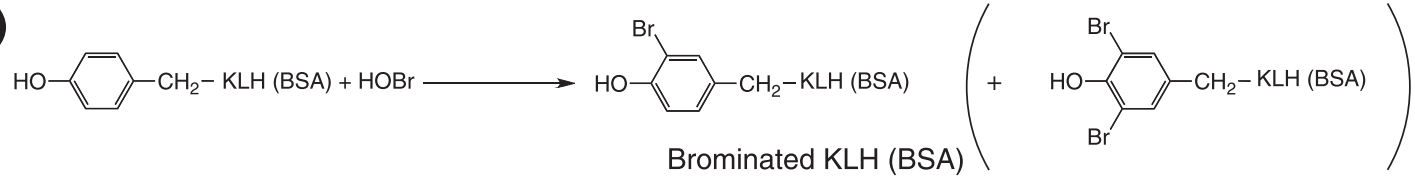

b)
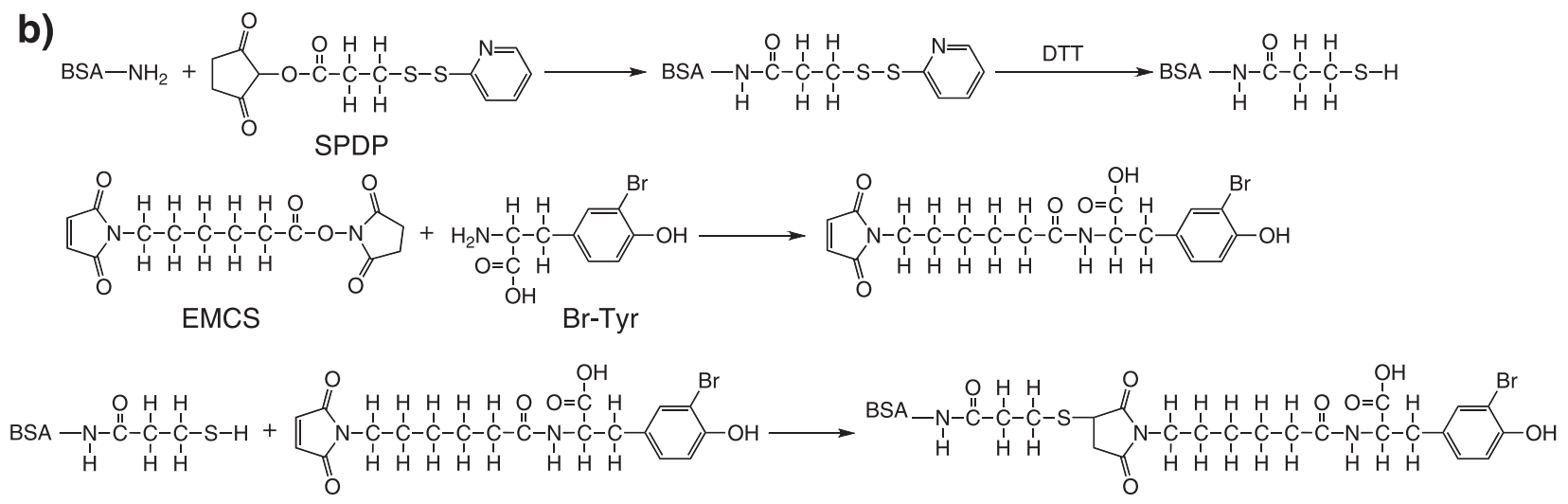

c)
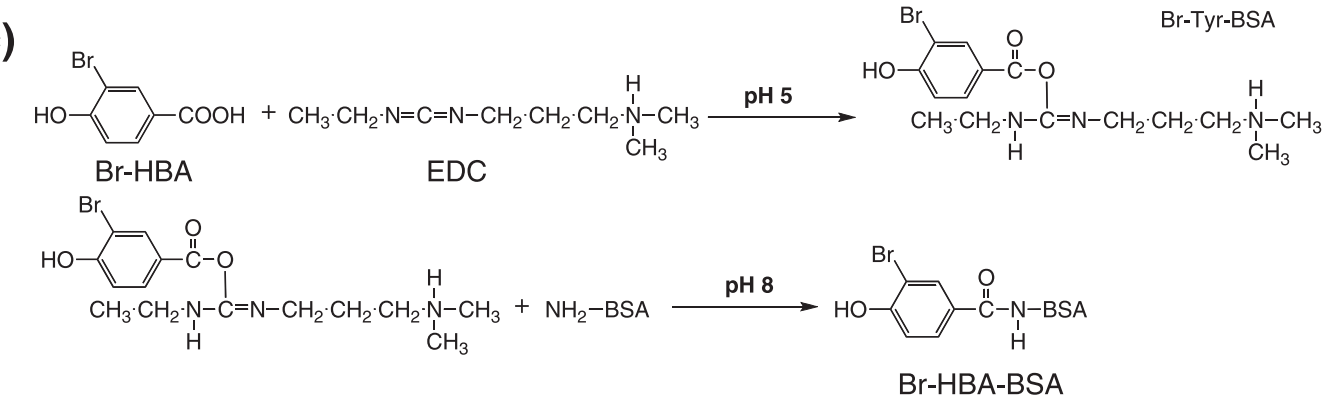

Fig. 1. Procedure for the synthesis of antigens. (A) Brominated KLH (BSA). (B) Modified Tyr-conjugated BSA. (C) Modified HBA-conjugated BSA.
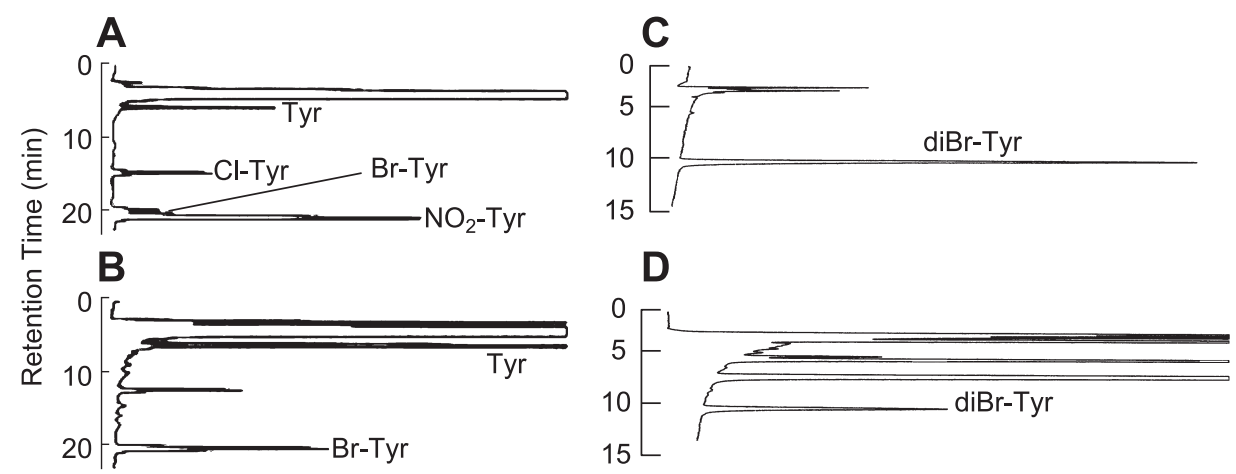

Fig. 2. HPLC analytical chromatograms of various modified Tyrs. (A, C) Standards. (B, D) Pronase hydrolysate of brominated KLH. (A, B) Analytical method for various modified Tyr residues. (C, D) Analytical method for diBr-Tyr.

\section{Characteristics of the antiserum: competitive ELISA}

To further confirm the antigen specificity of the antiserum, competitive ELISA was performed. When brominated BSA was used as an antigen, diBr-Tyr and dil-Tyr inhibited the recognition of the antigen by the antiserum (Fig. 5A). DiBrHBA also inhibited the recognition of brominated BSA by the antiserum (Fig. 5C). Comparable results were obtained when diBr-Tyr-conjugated BSA or chlorinated BSA was used as antigen (data not shown).

\section{Characteristics of the antiserum: Immunohistochemistry}

The antiserum was applied for immunohistochemical analysis. Part of a sample of rat peritoneal exudate cells was stained with Luxol fast blue, which selectively stains 

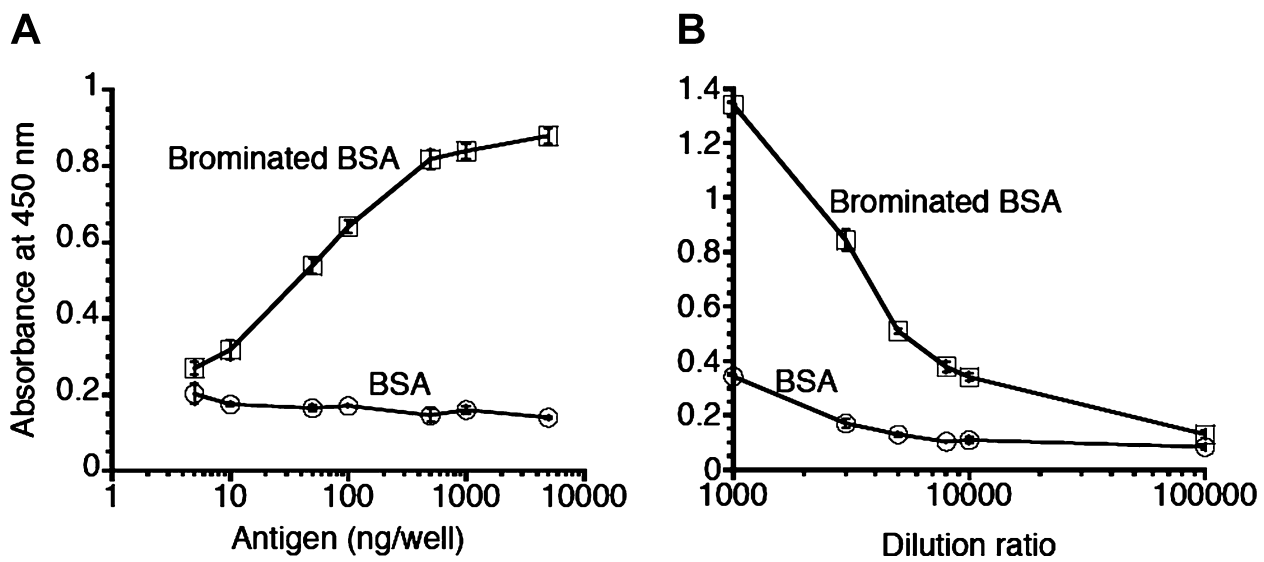

Fig. 3. Characteristics of the antiserum. (A) Reactivity of the antiserum. Each well was coated with 5 to $500 \mathrm{ng} / \mathrm{well}$ antigen (brominated BSA or BSA) and incubated with 3,000-fold-diluted antiserum. The results are expressed as mean \pm standard deviation $(n=3)$. Statistical analysis of the differences was performed by two-way ANOVA. Significant main effects of the concentration of antigen $(p<0.001)$ and the kind of antigen $(p<0.001)$ and significant interactive effect between the concentration of antigen and the kind of antigen $(p<0.001)$ are shown. (B) Titer of the antiserum. Each well was coated with $500 \mathrm{ng} /$ well antigen (brominated BSA or BSA) and incubated with 1,000 to 100,000-fold-diluted antiserum. The results are expressed as mean \pm standard deviation $(n=3)$. Statistical analysis of the differences was performed by two-way ANOVA. Significant main effects of the concentration of antigen $(p<0.001)$ and the kind of antigen $(p<0.001)$, and significant interactive effect between the concentration of antigen and the kind of antigen $(p<0.001)$ are shown.

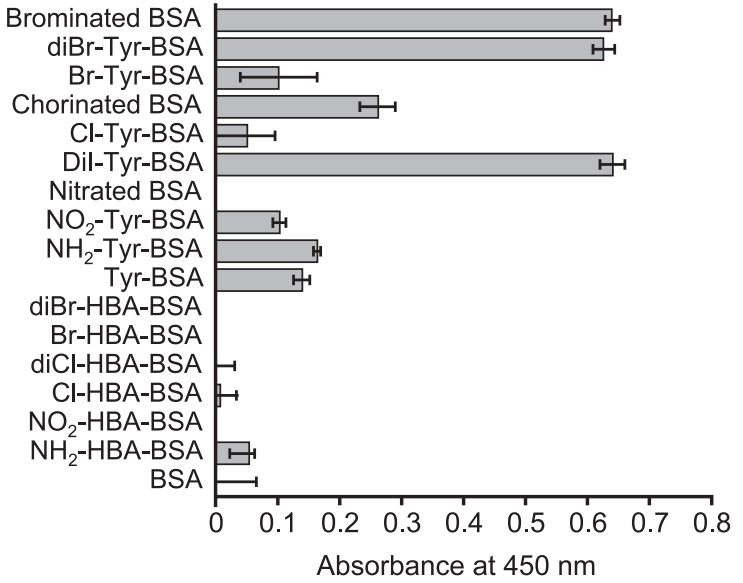

Fig. 4. The recognition of various modified tyrosines (Tyr) or hydroxybenzoic acids (HBA) in BSA by the antiserum. ELISA was performed to evaluate the specificity of the antiserum. Each well was coated with $500 \mathrm{ng} /$ well of antigen and incubated with 3,000-fold-diluted antiserum. The results are expressed as mean \pm standard deviation $(n=3)$. Statistical analysis of the differences was performed by one-way ANOVA $(p<0.001)$.

eosinophil granules (Fig. 6A). These cells had ring-shaped nuclei, which are characteristic of rat eosinophils (Fig. 6A). The physiological concentrations of $\mathrm{Br}^{-}$and nitrite in the plasma of healthy humans are $16-101 \mu \mathrm{M}$ [28] and $0.1-$ $20 \mu \mathrm{M}$ [29], respectively, and the concentration of $\mathrm{Cl}^{-}$in saline is $137 \mathrm{mM}$. In the inflammatory state, the concentra- tion of nitrite in the plasma increases. Therefore, $100 \mu \mathrm{M}$ $\mathrm{Br}^{-}, 140 \mathrm{mM} \mathrm{Cl}^{-}$, or $50 \mu \mathrm{M}$ nitrite was used to modify the rat eosinophils. Control and $\mathrm{H}_{2} \mathrm{O}_{2}$-treated eosinophils were not stained by the antiserum (Fig. 6B and C). This result indicates that the antiserum does not recognize the oxidative modification of tyrosine or other substrates. Brominated eosinophils were stained by the antiserum (Fig. 6D), whereas chlorinated cells and nitrated cells were not stained (Fig. 6E and F, respectively). The nitration of eosinophils on the slides by nitrite and $\mathrm{H}_{2} \mathrm{O}_{2}$ was confirmed by staining with anti-NO2-Tyr polyclonal antibody (data not shown).

\section{Discussion}

The rabbit antiserum obtained in the present study recognized diBr-Tyr in BSA. It reacted with diCl-Tyr in BSA. However, the antiserum specifically detected $\mathrm{HOBr}-$ modified protein of rat eosinophils in immunohistochemistry. This difference can be explained at least in part by the difference between the affinity of the antibody to diBr-Tyr and that to diCl-Tyr, the steric hindrance in the protein structure, the difference in protein species modified by the two chemicals $(\mathrm{HOBr}$ and $\mathrm{HOCl})$, and/or the difference in the site of the tyrosine residues in a protein modified by the two chemicals. The site-directed modification of tyrosine (nitration, chlorination, bromination, oxidation) has been reported previously [30-33].

The present results from the competitive ELISA indicate that the affinity of the antiserum to diBr-Tyr and diI-Tyr was 

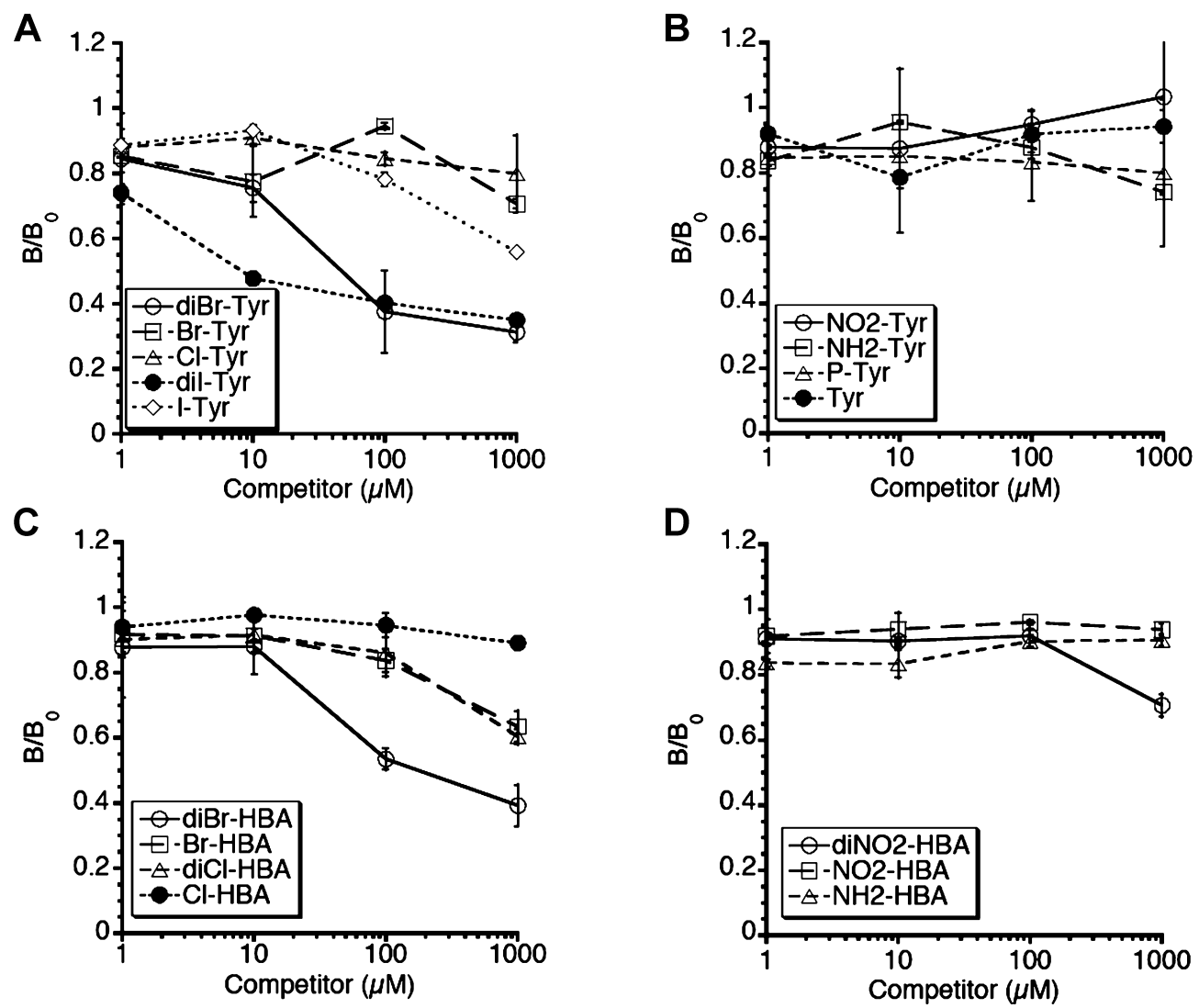

Fig. 5. Competitive ELISA using modified Tyrs and HBAs. The rabbit antiserum was preincubated with various concentrations of each modified Tyr or modified HBA. Each well was coated with $500 \mathrm{ng} /$ well of brominated BSA and incubated with 3,000-folddiluted antiserum. The results are expressed as the mean \pm standard deviation $(n=3)$. Statistical analysis of the differences was performed by two-way ANOVA. Significant main effects of the concentration of competitor $(p<0.001)$ and the kind of competitor $(p<0.001)$ and interactive effect between the concentration of competitor and the kind of competitor $(p<0.001)$ are shown.

strongest. The antiserum strongly recognized brominated BSA, diBr-Tyr-conjugated BSA, and diI-Tyr-conjugated BSA but only weakly recognized Br-Tyr-conjugated BSA and Cl-Tyr-conjugated BSA in the ELISA tests. $\mathrm{DiNO}_{2}-\mathrm{Tyr}$ could not be recognized by the antiserum since diNO$_{2}-\mathrm{Tyr}$ was probably produced during nitration of BSA by peroxynitrite and the antiserum did not recognize nitrated BSA. Thus, the epitope recognized by the antiserum is likely to be dihalogenated Tyr.

The antiserum weakly recognized $\mathrm{NO}_{2}$-Tyr-conjugated BSA at a similar level to Tyr-conjugated BSA by ELISA. Nitrated BSA was not recognized by the antiserum. These results suggest that the antiserum could recognize the tyrosine structure conjugated with the cross-linker but not the intrinsic tyrosine structure in BSA. Probably, the antiserum recognized $\mathrm{Br}$-Tyr-conjugated $\mathrm{BSA}, \mathrm{Cl}$-Tyr-conjugated $\mathrm{BSA}$, and $\mathrm{NH}_{2}$-Tyr-conjugated BSA by recognition of the cross-linked Tyr structure. The recognition of brominated BSA and chlorinated BSA by the antiserum showed that the antiserum could recognize dihalogenation of intrinsic tyrosine in protein.

The recognition of brominated BSA by the antiserum was inhibited by diBr-HBA, but the antiserum did not recognize diBr-HBA-conjugated BSA. The cause of this discrepancy may be steric hindrance due to binding of diBr-HBA to the cross-linker.

Several antibodies for halogenated tyrosine have been reported [8, 34-36]. Monoclonal anti-Cl-Tyr antibody (clone 2D10G9) raised against HOCl-modified low density lipoprotein $[34,36]$ also recognized $\mathrm{HOBr}$-treated BSA by western blotting analysis [37]. Moreover, a monoclonal antibody (clone 3A5) raised against $N$-bromosuccinimidemodified KLH recognized diBr-Tyr-conjugated BSA and HOCl-modified BSA as well as $N$-bromosuccinimidemodified BSA by ELISA [35]. The recognition of diBr-Tyrconjugated BSA by the antibody was inhibited by various (di)halogenated Tyrs and HBAs, such as diBr-Tyr, $N$ acetylchlorotyrosine, diI-Tyr, diBr-HBA, diCl-HBA, and Br-Tyr, using competitive ELISA [35]. The epitope of this antibody was assumed to be dihalogenated Tyr and HBA 


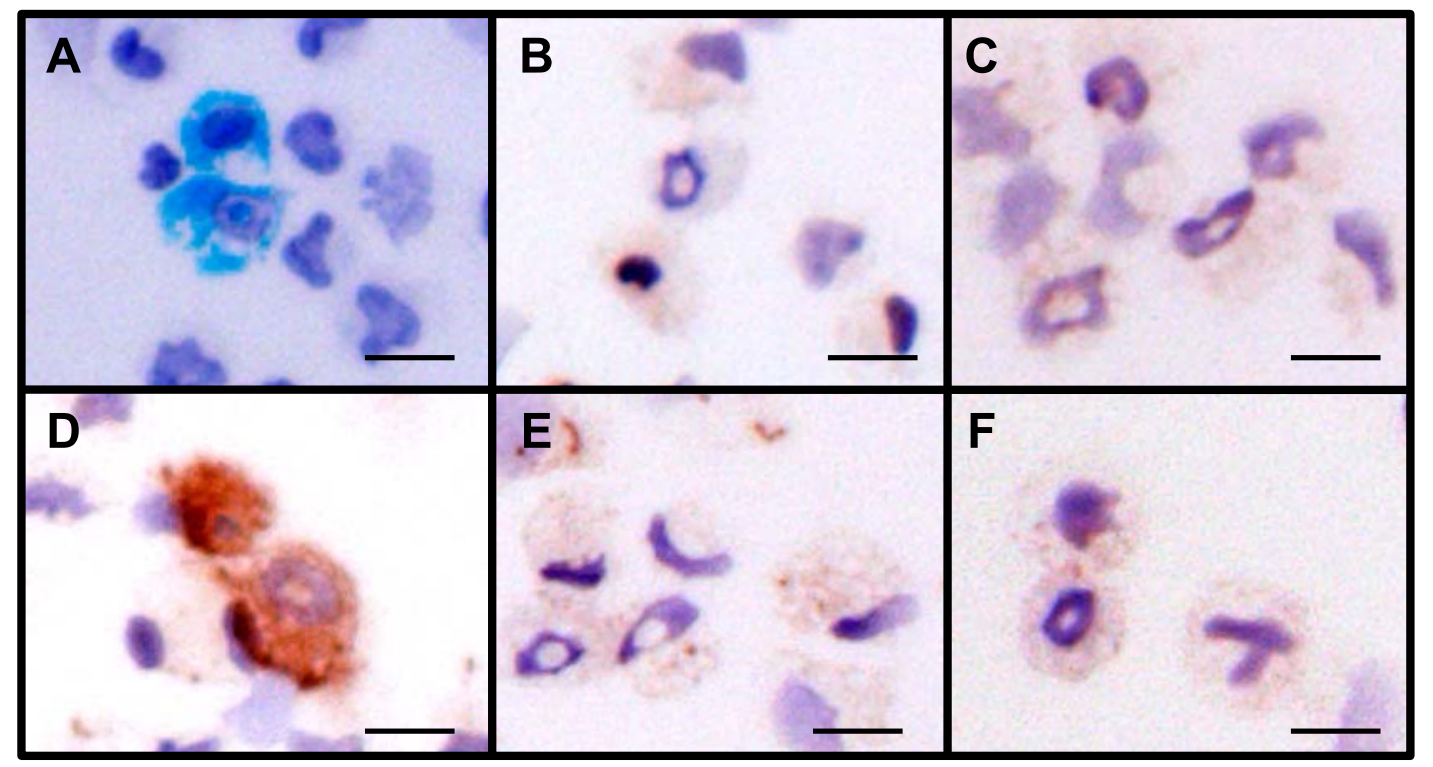

Fig. 6. Immunohistochemical staining of brominated protein in rat eosinophils. (A) Rat eosinophils were detected using Luxol fast blue staining. (B-E) Chemically treated specimens (eosinophil-containing cells) were incubated with 4,000-fold-diluted rabbit antiserum. (B) Control (100 $\mu \mathrm{M}$ DTPA). (C) $\mathrm{B}+100 \mu \mathrm{M} \mathrm{H}_{2} \mathrm{O}_{2}$. (D) $\mathrm{C}+100 \mu \mathrm{M} \mathrm{Br}^{-}$. (E) $\mathrm{C}+140 \mathrm{mM} \mathrm{Cl}^{-}$. (F) $\mathrm{C}+50 \mu \mathrm{M}$ nitrite. Scale bars represent $25 \mu \mathrm{m}$.

[35]. Thus, the discrimination of each of the (di)halogenated proteins by antibody may be difficult. Therefore, polyclonal anti-Cl-Tyr antibody raised against Cl-HBA-conjugated $\mathrm{KLH}$ [8] may also recognize various halogenated proteins, such as brominated protein. Our antiserum raised against HOBr-modified KLH also recognized various (di)halogenated Tyr (but not halogenated HBA) using ELISA. However, the antiserum specifically stained brominated rat eosinophils using an immunohistochemical method. The possibility that chlorination of rat eosinophils did not occur could not be denied in the present study because confirmation of the chlorination of rat eosinophils on a slide is difficult. Although the antibodies reported for halogenated tyrosine may recognize specific antigens immunohistochemically, this point has not been investigated.

It may be difficult to produce a specific antibody for (di)Br-Tyr in proteins because only one or two residues are different between (di)Br-Tyr and other modified tyrosine residues. In particular, the nature of one halogen is similar to other halogens.

This study attempted to make a specific anti-Br-Tyr antibody by immunization of Br-Tyr-conjugated $\mathrm{KLH}$ or $\mathrm{Br}$ HBA-conjugated KLH into a rabbit, but this proved not to be achievable. An antiserum that recognized diBr-Tyr was successfully recovered when brominated KLH was used as the immunogen. However, the antiserum did not recognize Br-Tyr. A previously reported monoclonal antibody also recognized dihalogenated $\mathrm{BSA}$, but not Br-Tyr-conjugated BSA [35]. Therefore, it may also be difficult to make an anti-
Br-Tyr antibody because of the probable weak characteristics of Br-Tyr as an epitope.

The content of Br-Tyr and Cl-Tyr on proteins in bronchoalveolar lavage fluid recovered from lung segments of asthmatic subjects was increased by allergen-challenge [38]. The levels of Br-Tyr and Cl-Tyr in the urine [22], endotracheal/bronchial aspirate [2], and sputum [21] in asthma patients were high. In these cases, diBr-Tyr and diClTyr could also be formed. In allergic diseases, activated eosinophils could produce (di)Br-Tyr. Inflammation could also occur in allergic diseases, neutrophils could be activated, and (di)Cl-Tyr may be formed. Therefore, the current antiserum can be used for the analysis of the pathogenesis in allergy diseases, although it was not a diBr-Tyr-specific antiserum.

\section{Acknowledgement}

This work was supported in part by a Grant-in-Aid for Scientific Research (C) 18590550 from the Ministry of Education, Culture, Sports, Science and Technology of Japan.

\section{Abbreviations}

Br-HBA, bromohydroxybenzoic acid; Br-Tyr, bromotyrosine; Cl-HBA, chlorohydroxybenzoic acid; Cl-Tyr, chlorotyrosine; diBr-HBA, dibromohydroxybenzoic acid; diBrTyr, dibromotyrosine; diCl-HBA, dichlorohydroxybenzoic acid; diBr-Tyr, dichlorotyrosine; DTPA, diethylenetriamine- 
$N, N, N^{\prime}, N^{\prime \prime}, N^{\prime \prime}$-pentaacetic acid; diNO2-HBA, dinitrohydroxybenzoic acid; dil-Tyr, di-iodotyrosine; EDC, 1-ethyl-3-(3dimethylaminopropyl) carbodiimide-HCl; EMCS, $N$-(6maleimidocaproyloxy)-succinimide; EPO, eosinophil peroxidase; I-Tyr, iodotyrosine; HBA, hydroxybenzoic acid; $\mathrm{KLH}$, keyhole limpet hemocyanin; MPO, myeloperoxidase; $\mathrm{NH}_{2}$-HBA, aminohydroxybenzoic acid; $\mathrm{NH}_{2}$-Tyr, aminotyrosine; $\mathrm{NO}_{2}$-HBA, nitrohydroxybenzoic acid; $\mathrm{NO}_{2}$-Tyr, nitrotyrosine; P-Tyr, phosphotyrosine; SPDP, $N$-succinimidyl 3-(2-pyridyldithio)propionate; Tyr, tyrosine.

\section{References}

[1] Wang, J. and Slungaard, A.: Role of eosinophil peroxidase in host defense and disease pathology. Arch. Biochem. Biophys., 445, 256-260, 2006.

[2] MacPherson, J.C., Comhair, S.A.A., Erzurum, S.C., Klein, D.F., Lipscomb, M.F., Kavuru, M.S., Samoszuk, M.K., and Hazen, S.L.: Eosinophils are a major source of nitric oxidederived oxidants in severe asthma: characterization of pathways available to eosinophils for generating reactive nitrogen species. J. Immunol., 166, 5763-5772, 2001.

[3] Kubo, M., Kambayashi, Y., Takemoto, K., Okuda, J., Muto, M., and Ogino, K.: Reactive nitrogen species formation in eosinophils and imbalance in nitric oxide metabolism are involved in atopic dermatitis-like skin lesions in $\mathrm{NC} / \mathrm{Nga}$ mice. Free Radic. Res., 39, 719-727, 2005.

[4] Shibamori, M., Ogino, K., Kambayashi, Y., and Ishiyama, H.: Intranasal mite allergen induces allergic asthma-like responses in NC/Nga mice. Life Sci., 78, 987-994, 2006.

[5] Takano, H., Yanagisawa, R., and Inoue, K.: Components of diesel exhaust particles diversely enhance a variety of respiratory diseases related to infection or allergy: extracted organic chemicals and the residual particles after extraction differently affect respiratory diseases. J. Clin. Biochem. Nutr., 40, 101-107, 2007.

[6] Hazen, S.L. and Heinecke, J.W.: 3-Chlorotyrosine, a specific marker of myeloperoxidase-catalyzed oxidation, is markedly elevated in low density lipoprotein isolated from human atherosclerotic intima. J. Clin. Invest., 99, 2075-2081, 1997.

[7] Buss, I.H., Senthilmohan, R., Darlow, B.A., Mogridge, N., Kettle, A.J., and Winterbourn, C.C.: 3-Chlorotyrosine as a marker of protein damage by myeloperoxidase in tracheal aspirates from preterm infants: association with adverse respiratory outcome. Pediatr. Res., 53, 455-462, 2003.

[8] Gujral, J.S., Hinson, J.A., Farhood, A., and Jaeschke, H.: NADPH oxidase-derived oxidant stress is critical for neutrophil cytotoxicity during endotoxemia. Am. J. Phys. Gastrointest. Liver Physiol., 287, G243-G252, 2004.

[9] Wu, W., Chen, Y., d'Avignon, A., and Hazen, S.L.: 3Bromotyrosine and 3,5-dibromotyrosine are major products of protein oxidation by eosinophil peroxidase: potential markers for eosinophil-dependent tissue injury in vivo. Biochemistry, 38, 3538-3548, 1999.

[10] Harrison, J.E. and Schultz, J.: Studies on the chlorinating activity of myeloperoxidase. J. Biol. Chem., 251, 1371-1374,
1976.

[11] Weiss, S.J., Klein, R., Slivka, A., and Wei, M.: Chlorination of taurine by human neutrophils. Evidence for hypochlorous acid generation. J. Clin. Invest., 70, 598-607, 1982.

[12] Foote, C.S., Goyne, T.E., and Lehrer, R.I.: Assessment of chlorination by human neutrophils. Nature, 301, 715-716, 1983.

[13] Mayeno, A.N., Curran, A.J., Roberts, R.L., and Foote, C.S.: Eosinophils preferentially use bromide to generate halogenating agents. J. Biol. Chem., 264, 5660-5668, 1989.

[14] van Dalen, C.J. and Kettle, A.J.: Substrates and products of eosinophil peroxidase. Biochem. J., 358, 233-239, 2001.

[15] Weiss, S.J., Test, S.T., Eckmann, C.M., Ross, D., and Regiani, S.: Brominating oxidants generated by human eosinophils. Science, 234, 200-203, 1986.

[16] Thomas, E.L., Bozeman, P.M., Jefferson, M.M., and King, C.C.: Oxidation of bromide by the human leukocyte enzymes myeloperoxidase and eosinophil peroxidase. Formation of bromamines. J. Biol. Chem., 270, 2906-2913, 1995.

[17] Furtmüller, P.G., Zederbauer, M., Jantschko, W., Helm, J., Bogner, M., Jakopitsch, C., and Obinger, C.: Active site structure and catalytic mechanisms of human peroxidases. Arch. Biochem. Biophys., 445, 199-213, 2006.

[18] Senthilmohan, R. and Kettle, A.J.: Bromination and chlorination reactions of myeloperoxidase at physiological concentrations of bromine and chloride. Arch. Biochem. Biophys., 445, 225-234, 2006.

[19] Spalteholz, H., Panasenko, O.M., and Arnhold, J.: Formation of reactive halide species by myeloperoxidase and eosinophil peroxidase. Arch. Biochem. Biophys., 445, 225-234, 2006.

[20] Brennan, M.L., Wu, W., Fu, X., Shen, Z., Song, W., Frost, H., Vadseth, C., Narine, L., Lenkiewicz, E., Borchers, M.T., Lusis, A.J., Lee, J.J., Lee, N.A., Abu-Soud, H.M., Ischiropoulos, H., and Hazen, S.L.: A tale of two controversies: defining both the role of peroxidases in nitrotyrosine formation in vivo using eosinophil peroxidase and myeloperoxidase-deficient mice, and the nature of peroxidasegenerated reactive nitrogen species. J. Biol. Chem., 277, 17415-17427, 2002.

[21] Aldridge, R.E., Chan, T., van Dalen, C.J., Senthilmohan, R., Winn, M., Venge, P., Town, G.I., and Kettle, A.J.: Eosinophil peroxidase produces hypobromous acid in the airways of stable asthmatics. Free Radic. Biol. Med., 33, 847-856, 2002.

[22] Mita, H., Higashi, N., Taniguchi, M., Higashi, A., Kawagishi, Y., and Akiyama, K.: Urinary 3-bromotyrosine and 3chlorotyrosine concentrations in asthmatic patients: lack of increase in 3-bromotysine concentration in urine and plasma proteins in aspirin-induced asthma after intravenous aspirin challenge. Clin. Exp. Allergy, 34, 931-938, 2004.

[23] Morris, J.C.: The acid ionization constant of $\mathrm{HOCl}$ from 5 to 35C. J. Phys. Chem., 70, 3798-3805, 1966.

[24] Wajon, J.E. and Morris, J.C.: Rates of formation of $N$-bromo amines in aqueous solution. Inorg. Chem., 21, 4258-4263, 1982.

[25] Koizumi, M., Endo, K., Kunimatsu, M., Sakahara, H., Nakashima, T., Kawamura, Y., Watanabe, Y., Saga, T., 
Konishi, J., Yamamuro, T., Hosoi, S., Toyama, S., Arano, Y., and Yokoyama, A.: ${ }^{67} \mathrm{Ga}$-labeled antibodies for immunoscintigraphy and evaluation of tumor targeting of drugantibody conjugates in mice. Cancer Res., 48, 1189-1194, 1988.

[26] Hinson, J.A., Michael, S.L., Ault, S.G., and Pumford, N.R.: Western blot analysis for nitrotyrosine protein adducts in livers of saline-treated and acetaminophen-treated mice. Toxicol. Sci., 53, 467-473, 2000.

[27] Seiler, G., Westerman, R.A., and Wilson, J.A.: The role of specific eosinophil granules in eosinophil-induced experimental encephalitis. Neurology, 19, 478-488, 1969.

[28] Holzbecher, J. and Ryan, D.E..: The rapid determination of total bromine and iodine in biological fluids by neutron activation. Clin. Biochem., 13, 277-278, 1980.

[29] Tsikas, D.: Methods of quantitative analysis of the nitric oxide metabolites nitrite and nitrate in human biological fluids. Free Radic. Res., 39, 797-815, 2005.

[30] Zheng, L., Settle, M., Brubaker, G., Schmitt, D., Hazen, S.L., Smith, J.D., and Kinter, M.: Localization of nitration and chlorination sites on apoprotein A-I catalyzed by myeloperoxidase in human atheroma and associated oxidative impairment in ABCA1-dependent cholesterol efflux from macrophages. J. Biol. Chem., 280, 38-47, 2005.

[31] Shao, B., Bergt, C., Fu, X., Green, P., Voss, J.C., Oda, M.N., Oram, J.F., and Heinecke, J.W.: Tyrosine 192 in apolipoprotein A-I is the major site of nitration and chlorination by myeloperoxidase, but only chlorination markedly impairs ABCA1-dependent cholesterol transport. J. Biol. Chem., 280, 5983-5993, 2005.

[32] Shao, B., Oda, M.N., Bergt, C., Fu, X., Green, P.S., Brot, N.,
Oram, J.F., and Heinecke, J.W.: Myeloperoxidase impairs ABCA1-dependent cholesterol efflux through methionine oxidation and site-specific tyrosine chlorination of apolipoprotein A-I. J. Biol. Chem., 281, 9001-9004, 2006.

[33] Salavej, P., Spalteholz, H., and Arnhold, J.: Modification of amino acid residues in human serum albumin by myeloperoxidase. Free Radic. Biol. Med., 40, 516-525, 2006.

[34] Malle, E., Hazell, L., Stocker, R., Sattler, W., Esterbauer, H., and Waeg, G.: Immunologic detection and measurement of hypochlorite-modified LDL with specific monoclonal antibodies. Arterioscler. Thromb. Vasc. Biol., 15, 982-989, 1995.

[35] Kato, Y., Kawai, Y., Morinaga, H., Kondo, H., Dozaki, N., Kitamoto, N., and Osawa, T.: Immunogenicity of a brominated protein and successive establishment of a monoclonal antibody to dihalogenated tyrosine. Free Radic. Biol, Med., 38, 24-31, 2005.

[36] Hasegawa, T., Malle, E., Farhood, A., and Jaeschke, H.: Generation of hypochlorite-modified proteins by neutrophils during ischemia-reperfusion injury in rat liver: attenuation by ischemic preconditioning. Am. J. Physiol. Gastrointest. Liver Physiol., 289, G760-G767, 2005.

[37] Chapman, A.L.P., Senthilmohan, R., Winterbourn, C.C., and Kettle, A.J.: Comparison of mono- and dichlorinated tyrosines with carbonyls for detection of hypochlorous acid modified proteins. Arch. Biochem. Biophys., 377, 95-100, 2000.

[38] Wu, W., Samoszuk, M.K., Comhair, S.A.A., Thomassen, M.J., Farver, C.F., Dweik, R.A., Kavuru, M.S., Erzurum, S.C., and Hazen, S.L.: Eosinophils generate brominating oxidants in allergen-induced asthma. J. Clin. Invest., 105, 1455-1463, 2000. 